\title{
Concentration and Unpredictability of Forecasts in Artificial Investment Games
}

\section{Xiu Chen, Fuhai Hong, and Xiaojian Zhao}

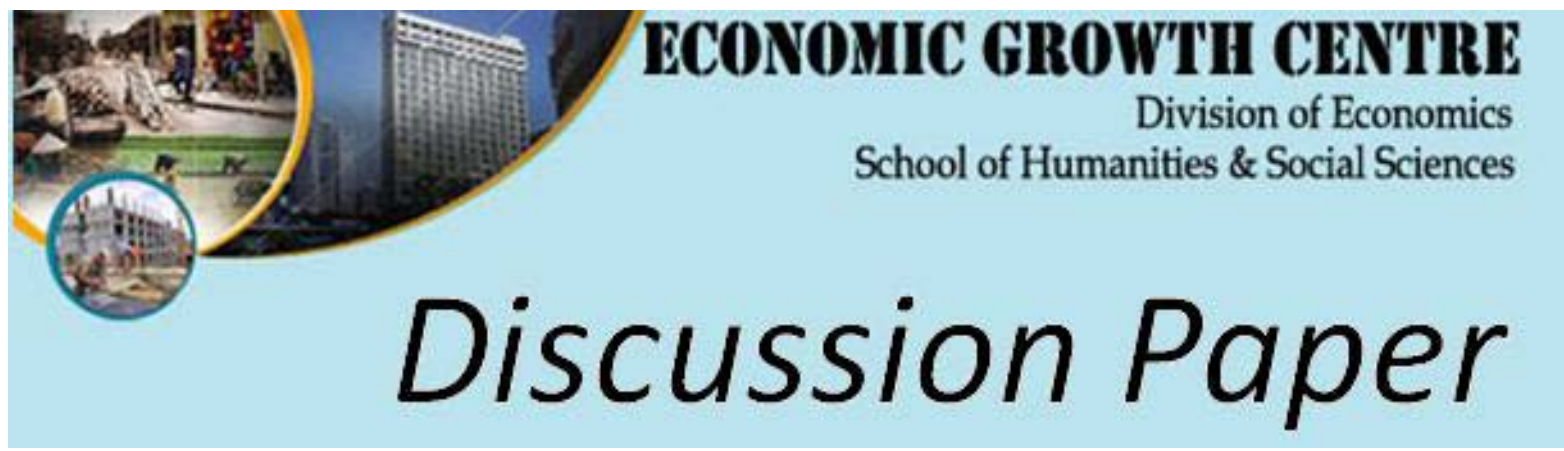


The author(s) bear sole responsibility for this paper.

Views expressed in this paper are those of the author(s) and not necessarily those of the Economic Growth Centre, NTU. 


\title{
Concentration and Unpredictability of Forecasts in
}

\author{
Artificial Investment Games*
}

\author{
Xiu Chen ${ }^{\dagger} \quad$ Fuhai Hong ${ }^{\ddagger} \quad$ Xiaojian Zhao ${ }^{\S}$
}

August 2016

\begin{abstract}
This paper investigates how people's forecasts about financial market are shaped by the environment, in which people interact before making investment decisions. By recruiting 1385 subjects on WeChat, one of the largest social media, we conduct an online experiment of artificial investment games. Our treatments manipulate whether subjects can observe others' forecasts and whether subjects engage in public or private investment decisions. We find that subjects' forecasts significantly converge when shared, though in different directions across groups. We also observe a strong positive correlation between forecasts and investments, suggesting that an individual's reported forecast is associated with his belief.
\end{abstract}

Keywords: forecast, investment, online experiment

JEL Classification: C90, D83, D84, G11

${ }^{*}$ We would like to thank Shenzhen Quantum Net Technology Co., LTD for sharing the WeChat users and providing web-based experimental programs for our study. We also gratefully acknowledge the excellent research assistance from Ran Kang and the support provided by Qianhai Institute for Innovative Research (QIIR). We also thank Yuk-fai Fong, Wooyoung Lim, Susheng Wang for stimulating discussions, and conference participants in the China Meeting of the Econometric Society (Chengdu) and seminar participants at Laboratory of Experimental Economics at Dongbei University of Finance and Economics (Dalian) and Hong Kong University of Science and Technology for their valuable comments.

$\dagger$ Department of Economics, Hong Kong University of Science and Technology, Hong Kong (xchenbc@connect.ust.hk).

${ }^{\ddagger}$ Division of Economics, Nanyang Technological University, Singapore (fhhong@ntu.edu.sg).

$\S$ Department of Economics, Hong Kong University of Science and Technology, Hong Kong (xjzhao81@gmail.com). 


\section{Introduction}

Information technology has greatly improved the information accessibility and transparency to people at the grassroot level. There are, however, two fundamental questions concerning the impact of the advancement of information technology on our economic or social life. First, with information sharing, do people form more converged opinions leading to less disputes on various economic or social issues? Second, does information accessibility help people form beliefs that are closer to the truth so as to make better decisions?

While pre-play communication is known to enhance efficiency in coordination and cooperation (reviewed in Section 2), we attempt to examine the effect of such cheap talk on investment decisions. In particular, we seek to explore whether pre-play communication would cause a convergence in individuals' forecasts about the performance of the financial market, forming collective beliefs, and influence their investment behaviors. A key question relevant to financial markets is whether investors' beliefs on financial performance would concentrate when communicated, and how. For example, under the slowdown of China's economic growth and the wobbling confidence of investors, does information sharing within a community affect investors' forecasts on the market? After being exposed to social media, do people have more converged beliefs, and are their forecasts closer to the truth? How would the effects, if any, depend on the informational and economic environment in which individuals interact?

On an online experimental basis, we study the social contagion of forecasts in an artificial investment game. Our experimental investigation addresses the following key questions:

- Within a group, can pre-play communication produce a concentration in individuals' forecasts on the financial market?

- If so, can pre-play communication consistently lead to a concentration on the correct forecast across groups?

We conduct an online experiment using WeChat as the platform, which is one of the 
biggest standalone messaging app and China's most popular online social network. Specifically, we recruit 1385 subjects online and design a between-subject experiment of a group-based artificial investment game. The payoff of the game relies on participants' investment decisions and the return multiplier determined by the opening price of Shanghai Composite Index (henceforth SCI) on Monday, November 30, 2015. The experiment started at 7:00 PM on Friday, November 27, 2015, after the stock market was closed, and ended at 9:00 AM on the next Monday, November 30, 2015, before the stock market was opened. In the game, we asked each subject to forecast the opening price of the SCI and to decide whether to invest or not.

We design a $2 \times 2 \times 2$ between-subject experiment. Firstly, to examine the effect of pre-play communication, in forecast sharing groups subjects can observe other players' forecasts of SCI, while in baseline groups, the subjects cannot. Secondly, two types of investment projects are introduced, with a subject's payoff dependent on other group members' investments in one of them (i.e. the interdependent project), and independent in the other (i.e. the independent project), in order to detect the potential over-reporting of forecasts caused by strategic motives to induce other players to invest. Lastly, we design two worlds with different mappings between the return multiplier of the game and the SCI as a robustness check.

We choose to perform an online experiment on WeChat instead of using standard laboratories for three reasons: 1) A more representative sample can be obtained for our study. In contrast to standard laboratory experiments, in which most of the subjects are recruited from university students who typically have little experience in financial investment, ${ }^{1}$ subjects from WeChat users are more representative of investors in the Chinese financial market, given that WeChat is the most popular messaging app in China (and perhaps the most popular one in the world in terms of the number of users) and that the financial market in China is dominated by retail investors. ${ }^{2}$ 2) Recruiting subjects from

\footnotetext{
${ }^{1}$ It has been shown that student subjects perform differently from subjects in the field in an experimental study of herd behavior in financial markets (Alevy, Haigh and List, 2007).

${ }^{2}$ As of May 2016, WeChat has over a billion created accounts, and 700 million active users, with more than 70 million outside of China; see the Wikipedia entry of WeChat. Retail investors conduct 85 percent of the stock market's transactions in China in 2015; see also the article "New Horizon Opening For China's Stock Market" by Thomson Reuters, available at http://share.thomsonreuters.com/
} 
WeChat allows us to achieve a large number of participants within a relatively short time compared to doing it in a laboratory, enhancing the reliability of our statistical results. 3) While all subjects were facing the same latest price of the stock market after the experiment started, it was still important to maintain all other conditions (including the related on-going media news) based on which subjects made decisions the same for all subjects. Due to the capacity of a laboratory, a laboratory experiment usually needs to be done with several successive sessions, which would create a time difference in subjects' decision making and thus contaminate the conditions, but conducting an online experiment solves this problem by allowing a large number of subjects to make choices online within the same time period. ${ }^{3}$

Our experimental results suggest strong evidence on both concentration of withingroup forecasts and unpredictability of the concentration across groups: compared to baseline groups, subjects in forecast sharing groups tend to concentrate on some forecasts, but the forecast of SCI that is concentrated on varies significantly across groups. Moreover, we observe strong positive correlation between a subject's forecast and his investment decision, which suggests that a subject's reported (cheap-talk) forecast in the pre-play communication is associated with his underlying belief, driving his subsequent investment behavior.

The paper is organized as follows. The next section reviews the related literature. Section 3 provides an overview of online experiments. Section 4 introduces our experimental design and procedure. Section 5 presents our experimental findings. The last section concludes.

\section{Relation to the Literature}

We study social learning by introducing pre-play communication to investment games. Studies on social learning have divergent opinions: On one hand, Charness and Sutter (2012) in their review paper suggest that groups are more cognitively sophisticated, and

${ }^{3}$ To further avoid information asymmetry among subjects, our experimental design allows subjects to come back any time and change their choices before the experiment is closed. 
thus make better decisions than individuals. On the other hand, following Brown (1986), Glaeser and Sunstein (2009) model group polarization, and suggest that information sharing appears to be worse than independent decision making when individual learning is non-Bayesian. Similarly, Mojzisch, Grouneva and Schulz-Hardt (2010) empirically identify distinct biases in group discussion of information. Relatedly, Bénabou (2013) and Bénabou (2015) coin the notion of groupthink and account for the formation of individually rational collective denial and willful blindness. ${ }^{4}$ There are also related topics on herd behavior and peer effect. Banerjee (1992) theoretically rationalizes herd behavior. Empirical works also confirm the existence of herd behavior and peer effect in both laboratories (Cipriani and Guarino, 2005) and fields (Grinblatt, Titman and Wermers, 1995; Bursztyn et al., 2014). Among the online studies, Salganik, Dodds and Watts (2006)'s investigation on social influence in an artificial cultural market is closest to our paper. ${ }^{5}$ In contrast to these papers, our work focuses on the cause and effect of concentrated forecasts in pre-play communication (rather than concentrated actions or preferences).

Our experimental results provide evidence on group polarization but show that group polarization is indeed unpredictable, giving rise to less reliable decisions. By utilizing WeChat, the most popular social media in China, we explore whether within-group information sharing enlightens collective wisdom. The potential of online social network in facilitating information diffusion and civic engagement in China has been documented in Zheng and $\mathrm{Wu}$ (2005). However, McGrath et al. (2012) question whether citizen engagement in the political process in such a speedy manner brings about well-thought-out choices or just rapid promises which could lead to constant societal frustration. Our experimental study suggests that though communication leads to a concentration in beliefs within a group, a group does not consistently converge to the correct belief, thus the effect of social media on producing collective wisdom is still in doubt.

\footnotetext{
${ }^{4}$ More recently, Bénabou and Tirole (2016) provide an overview on the topic of motivated beliefs and reasoning at both the individual and collective levels.

${ }^{5}$ Similar studies include Muchnik, Aral and Taylor (2013) who perform an experiment on a social news aggregation website and find that prior ratings create herding effects and significant bias in individual rating behavior.
} 
Our experiment also explores the effect of spillover of others' investment in an artificial investment game, which smacks of public good games. A wide range of theoretical and experimental studies have found that costless pre-play communication is effective in facilitating cooperation. Dawes, McTavish and Shaklee (1977) and Isaac and Walker (1988) are among the first providing experimental evidence of communication improving cooperation. Bochet, Page and Putterman (2006) extend the literature by comparing the efficacy of communication with that of punishment, and find that communication works more efficiently in sustaining cooperation. Chaudhuri and Paichayontvijit (2006) investigate different communication schemes and find that the communication of common knowledge improves cooperation most. While most of the existing papers focus on the effect of communication on cooperation in public goods provision when there is no uncertainty, we investigate, in the presence of uncertainty, a different channel by which pre-play communication affects the confidence on the return of public goods investment, and thus the investment behavior.

\section{Overview of Online Experiments}

Until recently, online experiments in economics and finance have been scarce, compared to the abundance of laboratory experiments. Field experiments on existing online platforms include Kramer, Guillory and Hancock (2014) on Facebook, and Horton, Rand and Zeckhauser (2011) and Berinsky, Huber and Lenz (2012) on MTurk. The way we conduct our experiment is close to that of the studies using online resources to build "online laboratory" (Hergueux and Jacquemet, 2014; Salganik, Dodds and Watts, 2006). We build our own temporary laboratory on WeChat, using it as a platform to recruit subjects, run experiments and make payments.

Horton, Rand and Zeckhauser (2011) and Berinsky, Huber and Lenz (2012) find that online experiments could reach the same internal validity and external validity as laboratory experiments. For internal validity, they test the problems such as inattentiveness and identification and conclude that these problems are insignificant and could be miti- 
gated. For external validity, they find online subjects even more representative than those offline. The consistent results they obtain from the same online and offline experimental frameworks lend support to the validity of our experiment.

There are other advantages of online experiments. It usually costs less to conduct an online experiment than a laboratory experiment by saving the money for laboratory maintenance and reducing the cost of payment to subjects (as subjects do not have to physically show up). In addition, the capacity constraint that a typical laboratory experiment has is also circumvented. While the benefits of online experiments are exploited, we take advantages of certain features of WeChat to avoid or mitigate some of the potential problems of online experiments, as discussed below.

Firstly, WeChat helps overcome one of the most concerned problems of online experiments: security and credibility of payments. In China, where consumer-to-consumer $(\mathrm{C} 2 \mathrm{C})$ online transactions are well developed, there are several widely-used and reliable online payment platforms, e.g., Alipay developed by Alibaba, one of the most popular online C2C marketplace in China (see Li and Zhou, 2014). Our incentivized online experiment is based on WeChat, another popular payment platform. As long as participants' WeChat IDs are available, it is convenient to make monetary transfers. This also makes our experiment more appealing to WeChat users by improving its credibility of monetary payments. Secondly, as WeChat is a cellphone-based app, all of our participants participated in our experiment on their cellphones, while many other online experiments are designed and conducted based on personal computers. The bright side is that it helps diversify our subject pool, because in China there are much more people using cellphones to access the Internet than those using desktops or laptops; thus the population using cellphones to access the Internet is more representative. ${ }^{6}$ However, the downside is the inattentiveness problem: people may pay less attention when they play on their cellphones. Although Horton, Rand and Zeckhauser (2011) and Berinsky, Huber and Lenz (2012) find that this problem is minor, we try to make our experimental design as clear

\footnotetext{
${ }^{6}$ See, e.g., "The 37th Statistical Report on Internet Development in China" by China Internet Network Information Center, available at: http://www1.cnnic.cn/IDR/ReportDownloads/201604/ P020160419390562421055.pdf.
} 
as possible to mitigate this problem. Thirdly, as the most common way to register as a WeChat user is by using one's cellphone number, it would help alleviate the identification problem that many other online experiments may encounter.

\section{Experimental Design and Procedure}

We design an artificial investment game to investigate whether there exists concentration of forecasts on the opening price of Shanghai Composite Index (SCI) on November 30, 2015 when the forecasts are shared, and if any, whether the concentration is closer to the truth. The payoff of a subject in the investment game depends on 1) the opening price of SCI on the day and 2) the subjects' subsequent investment decisions after the forecasting.

\subsection{Experimental Design}

In the investment game, a subject first chooses a range that he thinks to be most likely for the opening price of SCI on November 30, 2015 (the Forecasting Task). The closing price of SCI on November 28 before the experiment started was 3436.40. We provided subjects with several options from which we asked them to choose one. The following table shows the two sets of options provided in different treatments (as described later in this section):

Table 1: Options for the Forecasting Task

\begin{tabular}{|c|c|c|}
\hline Option & Set I & Set II \\
\hline \hline A & 3620.01 or above & 3560.01 or above \\
\hline B & 3560.01 to 3620 & 3480.01 to 3560 \\
\hline C & 3480.01 to 3560 & 3380.01 to 3480 \\
\hline D & 3380.01 to 3480 & 3300.01 to 3380 \\
\hline E & 3300.01 to 3380 & 3240.01 to 3300 \\
\hline F & 3300 or below & 3240 or below \\
\hline
\end{tabular}

The subject then decides on whether to invest 250 Renminbi Yuan (RMB), out of 500RMB endowment, to an artificial project, which will be described in details below (the Investment Task). 
Subjects are divided into groups. Our $2 \times 2 \times 2$ treatments vary in three dimensions.

The first is about whether the forecasts are shared among group members.

- Baseline: There is no information provided regarding how other group members' forecast;

- Forecast Sharing: The subjects can observe the distribution of forecasts of other group members.

Specifically, under the treatments with forecast sharing, a bar is placed to each option displaying the percentage of group members who have selected this option as their forecasts. (See the left bottom figure in Appendix A.)

Subjects in all treatments are allowed to come back any time before the deadline to change their forecasts as well as investment decisions. This means that under the treatments with forecast sharing, subjects can come back to view the latest distribution of forecasts. Therefore, the feature of forecast sharing provides an opportunity for subjects in these treatments to communicate their forecasts costlessly before making final investment decisions.

Secondly, we manipulate the payoff function of the investment game. In one set of treatments, we follow Bénabou (2013) and introduce a spillover of other group members' investment into the payoff function, so as to reflect the reality that each individual is embedded in some collective endeavor (e.g. a firm, a military unit) where his final welfare is determined by both his own action and those of others. However, the spillover may give the subject incentives to over-report his forecast when the costless pre-play communication is allowed, in order to induce his group members to invest. To identify the potential over-reporting of forecasts driven by such a strategic motive, in another set of treatments, a subject's payoff depends solely on the individual's investment decision as well as the SCI. Therefore, there are two types of investment projects:

- Interdependent (or public) projects:

$$
P A Y O F F=500-I N V E S T+m \times(I N V E S T+a v g . G I N V E S T)
$$


where $I N V E S T=250$ if the subject chooses to invest and 0 otherwise, $m$, which we call the return multiplier, is determined by the SCI opening price, as will be explained in details below, and avg.GINVEST is the average investment amount of the group. So in the interdependent project, there is a spillover of group members' investment, which is positive when $m>0$.

- Independent (or private) projects:

$$
P A Y O F F=500-I N V E S T+m \times I N V E S T
$$

In independent projects, subject's payoff is independently determined by his own investment decision and the SCI opening price.

The last dimension is designed for a robustness check, in which we have two worlds, World I and World II, with different return multipliers. In both worlds, the return multipliers are determined by the SCI opening price. The two worlds differ in the mapping from the SCI opening price to $m$ as shown in Table 2. Note that the SCI closing price on the day when the experiment started, i.e. 3436.40, corresponds to $m=40 \%$ in the World I, and $m=80 \%$ in the World II. We are then able to check the robustness of subjects' behavioral patterns under different economic conditions.

Under independent projects, an individual should choose to invest if he believes that the SCI opening price will be above 3560 in World I or above 3480 in World II. Under interdependent projects, although the individually rational decision is still to invest if and only if the SCI opening price is above 3560 in World I or above 3480 in World II, in the first best each player should invest if and only if the SCI opening price is above 3480 in World I or above 3380 in World II. 
Table 2: SCI and Corresponding Return Multiplier $m$

\begin{tabular}{|c|c|c|c|}
\hline \multicolumn{2}{|c|}{ World I } & \multicolumn{2}{c|}{ World II } \\
\hline \hline SCI & $m$ & SCI & $m$ \\
\hline 3620.01 or above & $160 \%$ & 3560.01 or above & $160 \%$ \\
\hline 3560.01 to 3620 & $120 \%$ & 3480.01 to 3560 & $120 \%$ \\
\hline 3480.01 to 3560 & $80 \%$ & 3380.01 to 3480 & $80 \%$ \\
\hline 3380.01 to 3480 & $40 \%$ & 3300.01 to 3380 & $40 \%$ \\
\hline 3300.01 to 3380 & $0 \%$ & 3240.01 to 3300 & $0 \%$ \\
\hline 3300 or below & $-40 \%$ & 3240 or below & $-40 \%$ \\
\hline
\end{tabular}

In total we have 28 groups. Table 3 shows the number of groups under each of the 8 treatments.

Table 3: Group Allocation

\begin{tabular}{|c|c|c|c|}
\hline \multicolumn{2}{|c|}{} & BASELINE & FORECAST SHARING \\
\hline \hline \multirow{2}{*}{ World I } & Interdependent Project & 1 & 6 \\
\cline { 2 - 4 } & Independent Project & 1 & 6 \\
\hline \multirow{2}{*}{ World II } & Interdependent Project & 1 & 6 \\
\cline { 2 - 4 } & Independent Project & 1 & 6 \\
\hline
\end{tabular}

Each subject is randomly assigned to one of the 28 groups. Subjects assigned in each of the baseline groups are twice as many as those in each of the forecast sharing groups. This allocation results in about 43 subjects in each of the 24 forecast sharing groups, and about 86 subjects in each of the 4 baseline groups. The reason for this allocation scheme is for the ease of our statistical analysis (discussed in Appendix C).

With the experiment design, we aim to test the following hypotheses:

Hypothesis 1: a) The forecast sharing groups display higher concentration in forecasts compared to the baseline groups. b) The forecast sharing groups have better forecasts compared to the baseline groups.

Hypothesis 1 claims that in the pre-play communication, subjects tend to suppress divergent forecasts, and reach a conformity with other group members. Such tendency would increase the concentration level of forecasts in forecast sharing groups. Moreover, if within-group information sharing leads to collective wisdom, the forecast sharing groups would perform better in the forecasting task than the baseline groups. 
If the spillover of the interdependent projects incentivizes the subjects to over-report their forecasts to induce other members to invest, then the subjects under the forecast sharing groups with interdependent projects would strategically report higher forecasts than those with independent projects and the baseline groups. This leads to the following hypothesis.

Hypothesis 2: The forecast sharing groups with interdependent projects report higher forecasts than those with independent projects and the baseline groups.

\subsection{Experimental Procedure}

The experiment started at 7:00 PM on Friday, November 27, 2015 and ended at 9:00 AM on the next Monday, November 30, 2015. We recruited subjects by circulating the link of the experiment webpage to the WeChat user population via several channels, one of which was with the help of Shenzhen Quantum Net Technology Co., LTD. We pushed the link to the WeChat users who had subscribed the official accounts operated by this company. All WeChat users receiving the link to the experiment could easily circulate it in their own social networks on WeChat.

Appendix A presents the cellphone screenshots of our experiment webpage for the treatment of Interdependent Project-Forecast Sharing-World II (Inter-FS-II). The instructions were written in Chinese as the targeted population was the WeChat users who are mostly Chinese. The English translation of the experimental instructions can be found in Appendix B.

A brief description of the investment game was presented in the first page, in which subjects were informed that they were randomly assigned to different groups. On the second page, subjects were informed that 6 of them would be randomly chosen after the game was closed and paid at the amount of their final payoffs in the game with RMB. Then they were provided with a detailed instruction of the game. Two examples of payoff calculation, in which the player chooses to invest and not respectively, were provided in the link below the instruction. On the top of the third page, we presented a figure 
displaying the SCI in the latest 5 days. Below that we provided an online calculator to assist subjects in calculating the payoff. In the calculator, we allowed subjects to adjust the level of SCI, to change the investment decision, and for subjects in the interdependent project, to vary the percentage of investors within the group, so as to see how the payoff was determined accordingly. Right after that, we asked the two questions, Question 1 on the forecast of the SCI opening price (i.e. the Forecasting Task) and Question 2 on the investment decision (i.e. the Investment Task), both of which were compulsory questions.

After the subjects completed the two tasks, they were asked to answer a questionnaire on their demographic information on the fourth page. At the end of the experiment on the fifth page, we reminded them that they could come back anytime before the deadline to view and change their choices.

A total of 1569 WeChat-user subjects were involved in the experiment while 1385 of them participated and completed the game. Table 4 summarizes the demographical statistics. The composition of our subjects is in general balanced in gender and is more representative compared to subjects in a laboratory in terms of residence, education level and annual household income. Table 4 also shows the distributions in terms of the three treatment dimensions.

\section{$5 \quad$ Experimental Results}

In the analysis below, we use the Herfindahl-Hirschman index (HHI) to examine the extent to which subjects' forecasts are concentrated within a group. Moreover, we use the index of dissimilarity to examine the similarity of forecasts across groups (discussed in details in Section 5.2).

\subsection{Concentration of Forecasts}

HHI is commonly used to measure market concentration, and is also widely applied to the study of various social issues, such as measuring the variability of individual's choice modes (see, e.g., Susilo and Axhausen, 2014). In our study, we use HHI to measure the 


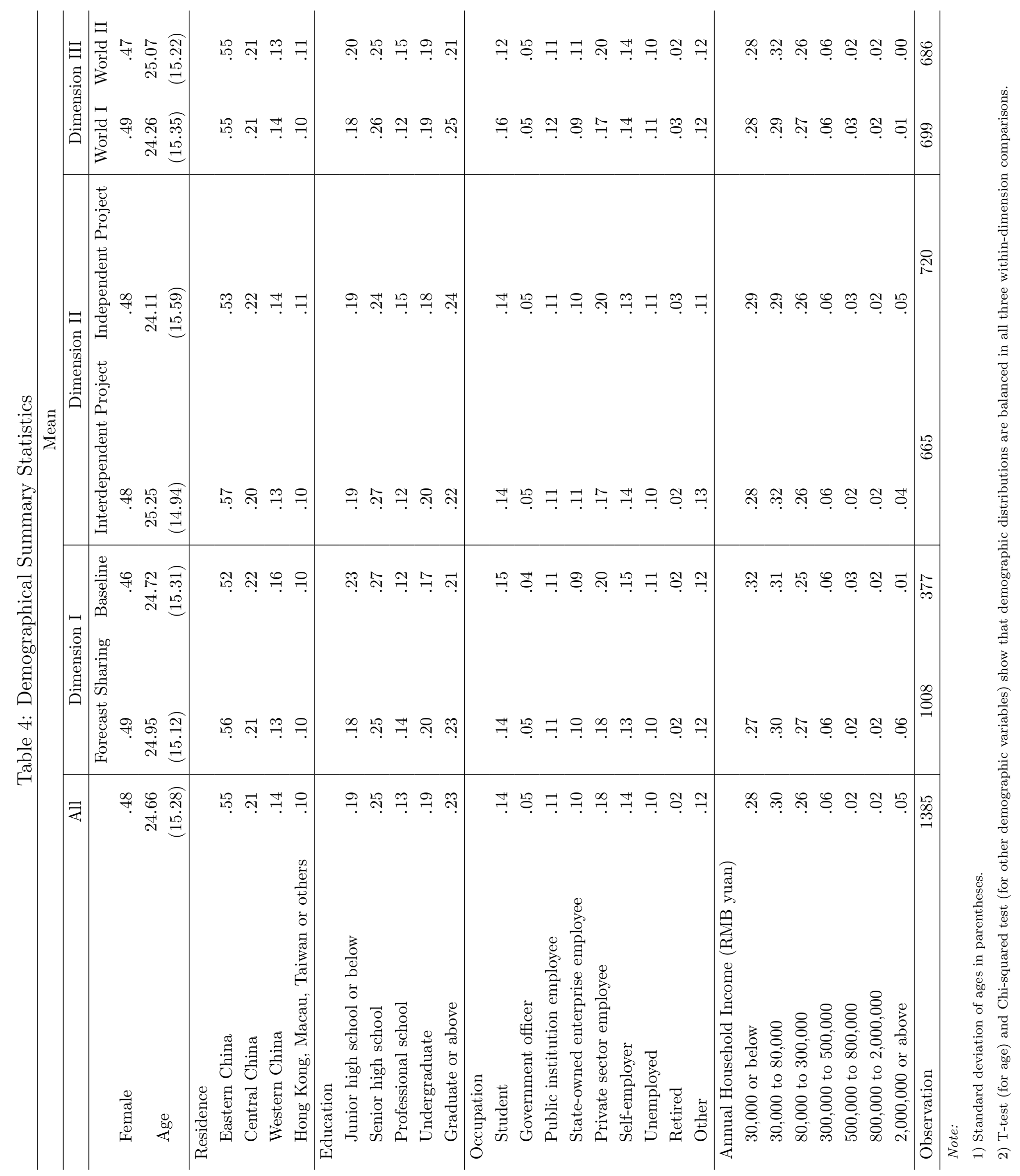


level of forecast concentration. To establish the index, we first calculate the share of each option in Question 1 (the Forecasting Task) that is selected by subjects,

$$
s_{i j}=\frac{c_{i j}}{\sum_{k=1}^{T} c_{k j}}
$$

where $c_{i j}$ is option $i$ 's selecting count in group $j$, and $T$ is the number of options.

We calculate HHI for each group as a measure of forecast concentration. HHI $H_{j}$ for group $j$ is expressed as:

$$
H_{j}=\sum_{i=1}^{T} s_{i j}^{2}
$$

so the higher the forecast concentration for group $j$, the closer $H_{j}$ is to 1 . Consider an extreme example when all participants in group $l$ select the same option $k$. Then option $k$ has share $s_{k l}=1$, and $H_{l}$ equals 1 . If the forecasts are dispersed, we would have a lower $H_{j}$. The lower bound for $H_{j}$ depends on $T$ : for our forecasting question, $H_{j}$ ranges from 0.17 to 1 .

Figure 1: Average HHI in World I and World II

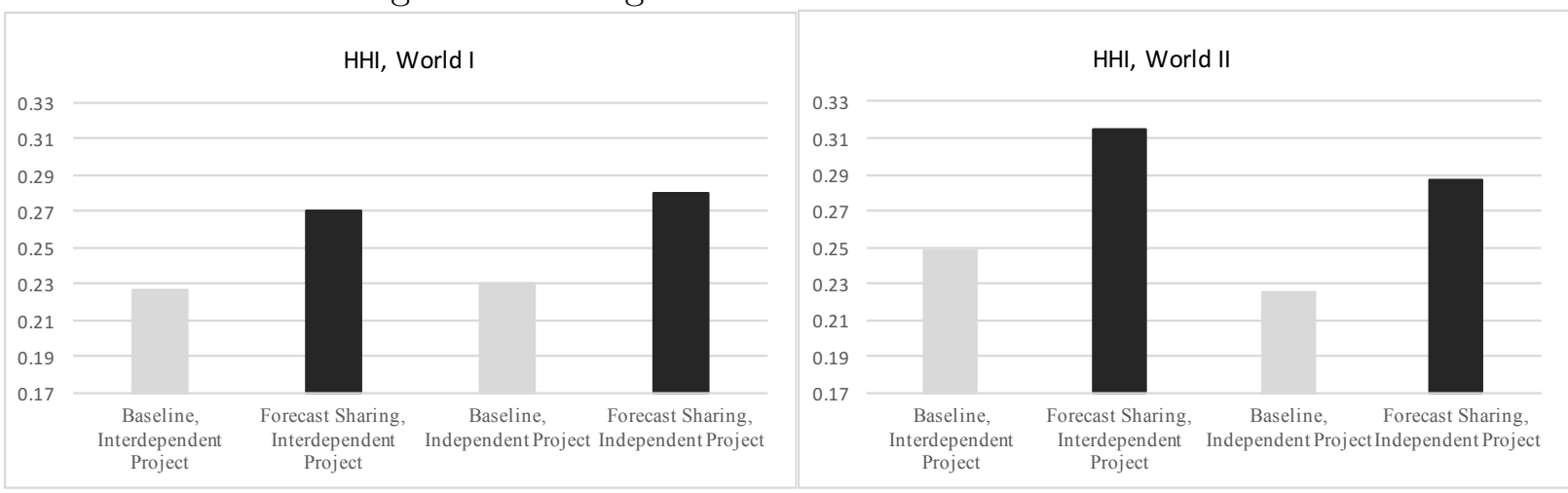

We use Mann-Whitney U test to compare the HHI of forecast sharing groups and of baseline groups in the cases of Interdependent Project in World I, Independent Project in World I, Interdependent Project in World II and Independent Project in World II respectively. Detailed procedure and full results are provided in Appendix C. Statistical results in Appendix C.1 suggest that the forecasts in forecast sharing group are significantly more concentrated within a group than the those in the baseline groups, in both worlds and for both interdependent and independent investment projects. We thus have 
our first result:

Result 1a: Forecasts in forecast sharing groups are significantly more concentrated than in baseline groups.

\subsection{Unpredictability: The Folly of Crowds}

We have shown by communication, subjects may form a collective forecast within a group. The next questions are whether communication would produce more correct forecasts, and whether this would affect investment. According to the opening price of SCI on November 30, 2015, 3433.86, the correct forecasts in our experimental setting are Option D in World I and Option C in World II, which correspond to the return multiplier $m=40 \%$ in World I and $m=80 \%$ in World II. With these realized return multipliers, the individually rational decision should be not to invest in both worlds, while the first best is not to invest in World I and to invest in World II.

We then look into the percentage of the correct forecasts and the percentage of not investing in each group. Figure 2 shows that in forecast sharing treatments, the percentage of the correct forecasts fluctuates across groups, so does the percentage of not investing in Figure 3. We conduct the Fischer's exact test for each of the following types of projects, independent projects in World I, interdependent projects in World I, independent projects in World II, and interdependent projects in World II, and find that in all the four types of the projects, there is no statistical significance between the players with forecast sharing and those in the baseline, in terms the frequency of choosing the correct forecast or the frequency of choosing the not-to-invest decision ( $p$ values $>0.1)$. In other words, although forecast sharing leads to a converged forecast among group members, subjects do not necessarily converge to the correct forecasts, neither do they make better individual investment decisions nor get closer to the first best outcome. 
Figure 2: Percentages of the Correct Forecasts
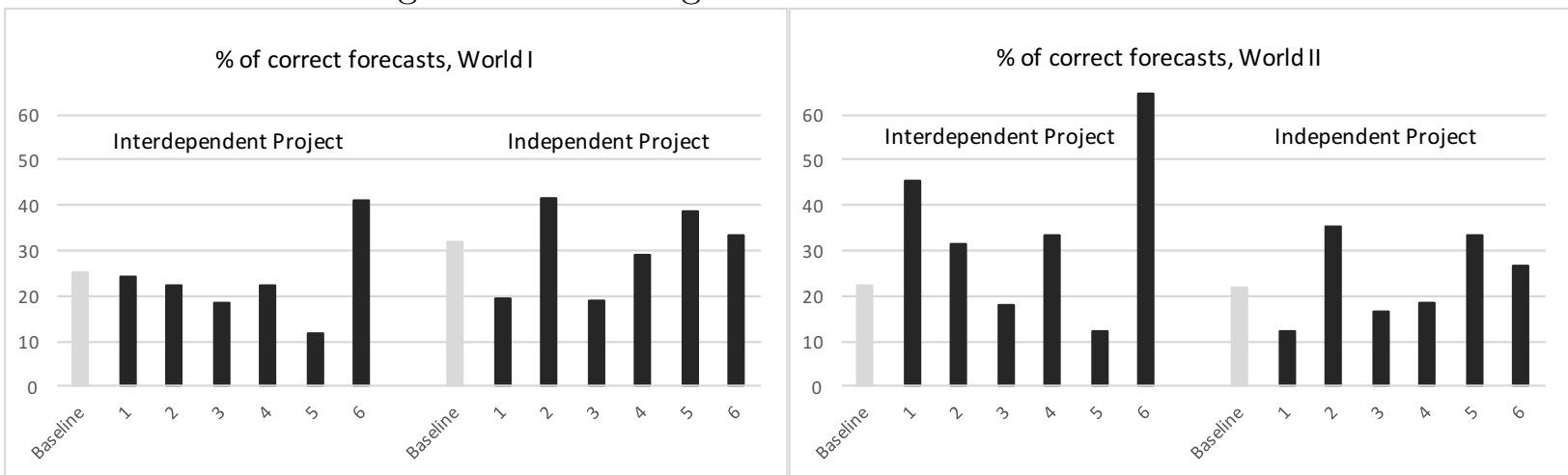

Notes: The numbers $1,2, \ldots 6$ indicate the numbers of the forecasting-sharing groups respectively.

Figure 3: Percentages of Not-to-Invest Decisions

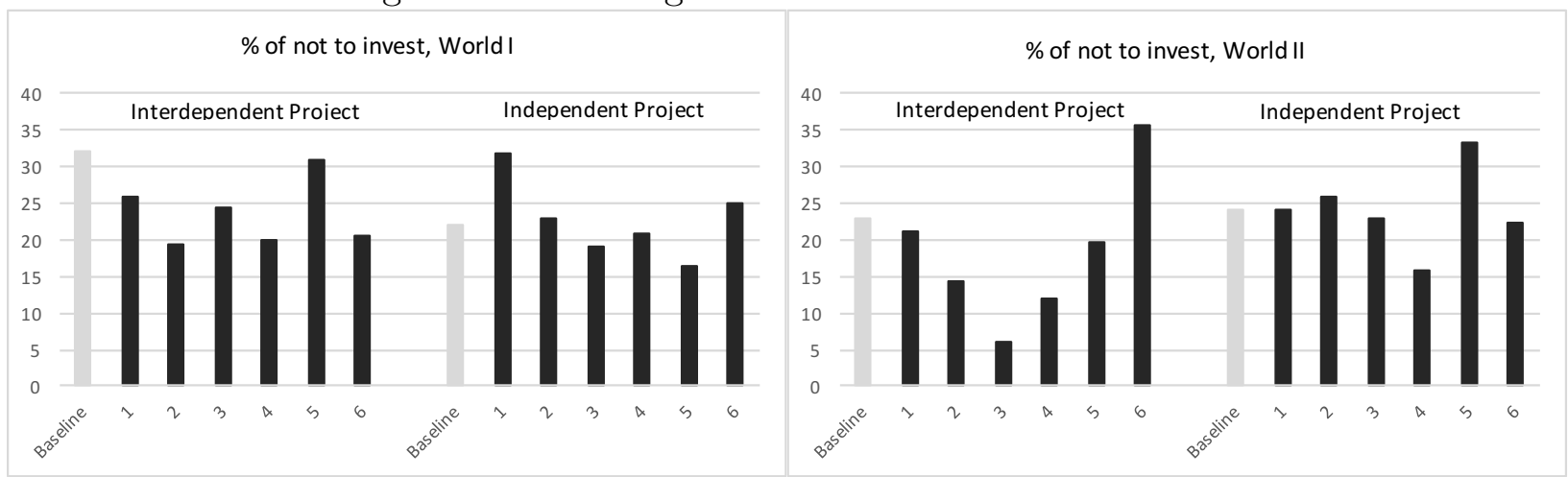

Notes: The numbers $1,2, \ldots 6$ indicate the numbers of the forecasting-sharing groups respectively.

We adopt the index of dissimilarity to measure the variation of forecasts across groups. Index of dissimilarity is first introduced by Cutler, Glaeser and Vigdor (1999) measuring the residential segregation, of two groups of people distributed across areas. Gentzkow and Shapiro (2011) also use it to capture the extent to which liberals and conservatives are exposed to different facts and opinions. Here in our study, we use the dissimilarity index to measure the extent to which different options are selected disproportionately by subjects in different groups. Thus larger index of dissimilarity indicates more unpredictable choices of the subjects . The index of dissimilarity for option $i$, or the option dissimilarity is calculated as

$$
\text { option dissimilarity } i=\frac{1}{2} \sum_{j=1}^{G}\left|\frac{c_{i j}}{c_{i}}-\frac{d_{i j}}{d_{i}}\right|
$$

where $c_{i j}$ is option $i$ 's selecting count in group $j, c_{i}$ is option $i$ 's selecting count in all groups, $d_{i j}$ is the selecting count of all the options other than $i$ in group $j$, and $d_{i}$ is 
the selecting count of all the options other than $i$ in all groups. $G$ is the total number of groups in the treatment. The index ranges from 0 , when selection of option $i$ is just as balanced among all groups as the selection of other options, to 1, when option $i$ is selected by everyone in some groups but not at all in other groups.

Figure 4: Option Dissimilarity for the Correct Options in World I and World II

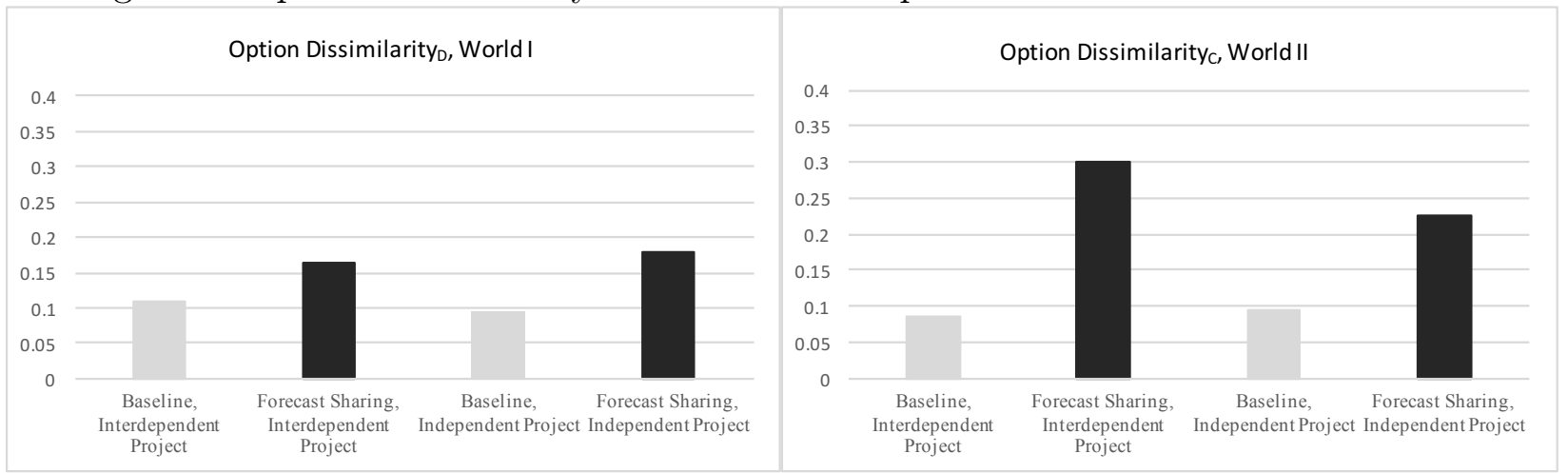

By conducting statistical comparison between the baseline and the forecast sharing treatments in the four cases respectively, we find that option dissimilarities for the correct answers in forecast sharing treatments are higher than in the baseline treatments, although statistical results in Appendix C.2 suggest the differences are not significant in most of the cases. It at least suggests that the pre-play communication does not make the correct forecast more stable across groups.

In the comparison of the index for the whole treatment, the treatment dissimilarity is the average of the $T$ option dissimilarities:

$$
\text { treatment dissimilarity }=\frac{1}{T} \sum_{k=1}^{T} \text { option dissimilarity }_{i}
$$

where $T$ is the total number of options. 
Figure 5: Treatment Dissimilarity in World I and World II

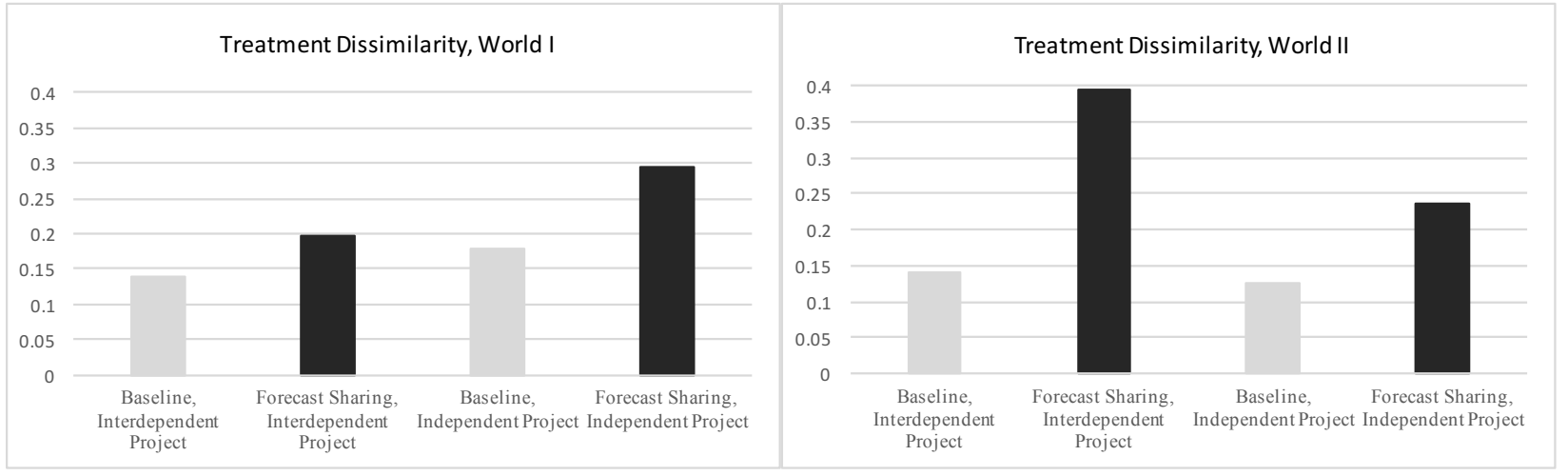

Figure 5 displays the comparison of treatment dissimilarities between the baseline and the forecast sharing treatments. A higher dissimilarity means the imbalance of forecasts across groups is higher, leading to a higher unpredictability. Again, we compare the treatment dissimilarities using Mann-Whitney $\mathrm{U}$ test in the four cases (as described in Appendix C.2). The results show that the forecast sharing treatments display significantly higher treatment dissimilarities than the baseline treatments. That is, while subjects who communicate tend to concentrate on some option as indicated by the higher HHI, subjects in different groups concentrate on different options. Hence, instead of producing collective wisdom, forecast sharing leads to more unpredictable forecasts across groups.

The analysis on the index of dissimilarity suggests the following result:

Result 1b: The forecasts of subjects in forecast sharing treatments are significantly more unpredictable across groups than in baseline treatments.

\subsection{Forecasts and Investments}

So far we have mainly focused on forecasts. In this subsection, we look into both forecasts and investment behavior as well as their connections with regression analysis.

Regressions on Forecasts We first look into the potential existence of over-reporting of forecasts caused by the strategic motive discussed above. As explained in Section 4.1, it can be seen from a comparison of the interdependent and independent projects. To this end, we run ordinal logistic regressions of players' forecasts on dummy variables $F S$ 
and $I N T E R$, with $F S=1$ for forecast sharing and $I N T E R=1$ for the interdependent project, and their interaction term, controlling for all the demographic variables, and group dummy variables.

Table 5: Regression Results on Forecasts

\begin{tabular}{lcc}
\hline forecast & World I & World II \\
\hline$F S$ & .2964 & -.4554 \\
& $(.4472)$ & $(.4297)$ \\
INTER & -.2360 & -.1635 \\
& $(.3000)$ & $(.2795)$ \\
$F S \cdot I N T E R$ & -.9483 & .1179 \\
& $(.5985)$ & $(.5175)$ \\
\hline Test of linear restrictions [p-value] & \\
INTER+FS INTER $=0$ & 0.2603 & 0.9150 \\
$F S+F S \cdot I N T E R=0$ & 0.0950 & 0.2646 \\
\hline Control Variables & YES & YES \\
\hline Pseudo $R^{2}$ & .0256 & .0435 \\
\hline Observation & 699 & 686 \\
\hline \hline Notes: & &
\end{tabular}

1) This table presents ordinal logistic regressions of forecasts on dummies denoting forecast sharing treatments and interdependent projects, and their interaction term.

2) Control variables include all the demographic variables and the group fixed effects.

3) The first column uses data in World I while the second column uses data in World II.

4) Heteroskedasticity robust standard errors are presented in parentheses.

${ }^{*}, * *$, and ${ }^{* * *}$ represent significance at $0.05,0.01$, and 0.001 levels respectively.

Table 5 reports the regression results. The first column uses data in World I while the second column uses data in World II. The sum of the coefficients of FS and FS INTER represents the effect of forecast sharing on players' forecasts, which is only marginally significant in World I (with $p$ value $=0.095$ ) and insignificant in World II, consistent with the above finding that the direction of the effect of forecast sharing on forecasts is not unambiguous. The sum of the coefficients of INTER and FS.INTER represents the effect of payoff interdependence on players' forecasts, which is not statistically significant in both worlds. The insignificance of the coefficient of FS INTER implies that given forecast sharing, the players in the treatment with payoff interdependence do not report higher forecasts than those with independent projects. 
Result 2: Given forecast sharing, the players in the treatment with payoff interdependence do not report higher forecasts than those with independent projects.

Regressions on Investments We then look at investment behavior. Other things equal, if players have social preferences such as altruism or efficiency concern, they would be more likely to invest in interdependent projects than in independent projects. Our regressions on investment serve two purposes: 1) to test this possibility, and 2) to explore the correlation between forecasts and investments.

Table 6: Regression Results on Investment

\begin{tabular}{|c|c|c|c|c|}
\hline \multirow[t]{2}{*}{ Investment } & \multicolumn{2}{|c|}{ World I } & \multicolumn{2}{|c|}{ World II } \\
\hline & $(1)$ & $(2)$ & $(3)$ & $(4)$ \\
\hline \multirow{2}{*}{$F S$} & .0261 & -.0906 & .0674 & .3233 \\
\hline & $(.4543)$ & $(.4531)$ & $(.4611)$ & $(.5113)$ \\
\hline \multirow{2}{*}{ INTER } & -.4453 & -.4298 & .0736 & .1419 \\
\hline & $(.3605)$ & $(.3860)$ & $(.3578)$ & $(.3763)$ \\
\hline$F S \cdot I N T E R$ & $\begin{array}{l}.4945 \\
(.6629)\end{array}$ & $\begin{array}{l}0.9752 \\
(.6866)\end{array}$ & $\begin{array}{l}-.5032 \\
(.6519)\end{array}$ & $\begin{array}{l}-.6696 \\
(.7174)\end{array}$ \\
\hline$f_{E}$ & - & $\begin{array}{l}.6431 \\
(.6176)\end{array}$ & - & $\begin{array}{l}-.0315 \\
(.6522)\end{array}$ \\
\hline$f_{D}$ & - & $\begin{array}{c}1.5399 * * \\
(.4556)\end{array}$ & $\begin{array}{lll}- & \\
\end{array}$ & $\begin{array}{l}1.2114^{*} \\
(.5310)\end{array}$ \\
\hline$f_{C}$ & - & $\begin{array}{c}2.0338^{* * *} \\
(.4613)\end{array}$ & - & $\begin{array}{c}1.2587^{*} \\
(.5042)\end{array}$ \\
\hline$f_{B}$ & - & $\begin{array}{c}2.9373^{* * *} \\
(.5269)\end{array}$ & - & $\begin{array}{c}2.2879 * * * \\
\quad(.5315)\end{array}$ \\
\hline$f_{A}$ & - & $\begin{array}{c}2.9922^{* * *} \\
(.5487)\end{array}$ & - & $\begin{array}{c}2.5564^{* * * *} \\
(.5629)\end{array}$ \\
\hline \multicolumn{5}{|c|}{ Test of linear restrictions [p-value] } \\
\hline$f_{A}=f_{B}=f_{C}=f_{D}=f_{E}$ & - & .0000 & - & .0000 \\
\hline Control Variables & YES & YES & YES & YES \\
\hline Pseudo $R^{2}$ & .0578 & .1442 & .0957 & .1700 \\
\hline Observation & 699 & 699 & 686 & 686 \\
\hline \multicolumn{5}{|l|}{ Notes: } \\
\hline \multicolumn{5}{|c|}{$\begin{array}{l}\text { 1) This table presents logistic regressions of investment on dummies denoting fore- } \\
\text { cast sharing treatments and interdependent projects, and their interaction term. In } \\
\text { column }(2) \text { and }(4) \text {, dummy variables denoting the selections in the Forecasting Task } \\
\left(f_{A} \ldots f_{E} \text { denote the selection in the Forecasting Task }\right. \\
\text { being option A to option E respectively) are included. }\end{array}$} \\
\hline \multicolumn{5}{|c|}{ 2) Control variables include all the demographic variables and the group fixed effects. } \\
\hline \multicolumn{5}{|c|}{ 3) The first two columns use data in World I while the last two columns use data in World II } \\
\hline \multicolumn{5}{|c|}{$\begin{array}{l}\text { 4) Heteroskedasticity robust standard errors are presented inside parentheses. }{ }^{*},{ }^{* *} \text {, } \\
\text { and }{ }^{* * *} \text { represent significance at } 0.05,0.01 \text {, and } 0.001 \text { levels, respectively. }\end{array}$} \\
\hline
\end{tabular}


Table 6 reports results from logit regressions of investment decisions. The first and third columns control for FS, FS and FS I INTER as well as demographical variables and group fixed effects, and the second and fourth columns further control for dummy variables on the players forecasts, $f_{E}-f_{A}$ (with an increasing order). The first two columns use data in World I while the last two columns use data in World II. In none of the regressions, the coefficients of the treatment variables, FS, FS and FS INTER are statistically significant. This implies that the players in the interdependent projects do not invest more often than those in the independent projects, other things equal. However, Column (2) and (4) reveal a substantial and positive correlation between forecasts and investment decisions: four out of five coefficients of the forecast variables are significant; and the coefficients increase in forecasts. Moreover, the tests of linear restrictions show that the coefficients for $f_{j}$ are significantly different from each other. These results indicate that there exists a significant increase in the likelihood of investment as forecasts increase.

Result 3: Forecasts reported in pre-play communication are significantly and positively associated with investment decisions.

The positive correlation suggests that the (cheap-talk) forecasts reported in the costless communication are associated with individuals' underlying beliefs.

\section{Conclusion}

This paper explores how individual forecasts associated with investment behaviors are influenced by the environment of information sharing. In particular, we focus on the role of a costless pre-play communication. Our online experimental evidence shows that with information sharing, people's forecasts tend to converge. However, communication does not necessarily lead to collective wisdom. In fact, the direction of the convergence may vary, so the collective forecast becomes less predictable.

Meanwhile, we confirm that the forecasts reported in the costless pre-play communication are significantly and positively correlated with the investment decisions, which 
suggests that the forecasts are associated with subjects' underlying beliefs. Our results thus suggest the concentration and unpredictability of individual beliefs when forecasts are shared.

Our paper can be regarded as the first one of exploring the WeChat platform for experimental studies. This platform may allow us to further study related dynamic issues such as social learning and contagious manias in financial markets followed by a crash, in which the traditional experimental method in the laboratory with a very limited number of subjects appears to be almost infeasible. ${ }^{7}$ Our experiment via WeChat thus showcases a promising experimental approach to study massive-scale economic and financial systems.

\footnotetext{
${ }^{7}$ There have been empirical studies using non-experimental methods to examine the role of contagious beliefs in financial frenzies and crashes. For example, Cheng, Raina and Xiong (2014) find that driven by the stake-dependent belief financial market "insiders" tend to buy high and sell low, resulting in a lower overall return on their own real-estate portfolios. Kandel and Pearson (1995) provide empirical evidence advocating the effect of heterogenous beliefs on trading.
} 


\section{References}

[1] Alevy, J. E., Haigh, M. S. and List, J. A. (2007). Information Cascades: Evidence from a Field Experiment with Financial Market Professionals. Journal of Finance, $62(1), 151-180$.

[2] Banerjee, A. V. (1992). A Simple Model of Herd Behavior. Quarterly Journal of Economics, 107(3), 797-817.

[3] Bénabou, R. (2013). Groupthink: Collective Delusions in Organizations and Markets. Review of Economic Studies, 80(2), 429-462.

[4] Bénabou, R. (2015). The Economics of Motivated Beliefs. Revue d'économie politique, 125(5), 665-685.

[5] Bénabou, R. and Tirole, J. (2016). Mindful Economics: The Production, Consumption and Value of Beliefs. Journal of Economic Perspectives, 30(3), 141-164.

[6] Berinsky, A. J., Huber, G. A. and Lenz, G. S. (2012). Evaluating Online Labor Markets for Experimental Research: Amazon.com's Mechanical Turk. Political Analysis, $20(3), 351-368$.

[7] Brown, R. (1986). Group Polarization. Social Psychology. Free Press, New York, 200-248.

[8] Bochet, O., Page, T. and Putterman, L. (2006). Communication and Punishment in Voluntary Contribution Experiments. Journal of Economic Behavior \& Organization, 60(1), 11-26.

[9] Bursztyn, L., Ederer, F., Ferman, B. and Yuchtman, N. (2014). Understanding Mechanisms Underlying Peer Effects: Evidence From a Field Experiment on Financial Decisions. Econometrica, 82(4), 1273-1301.

[10] Charness, G. and Sutter, M. (2012). Groups Make Better Self-Interested Decisions. Journal of Economic Perspectives, 26(3), 157-176. 
[11] Chaudhuri, A., and Paichayontvijit, T. (2006). Conditional Cooperation and Voluntary Contributions to a Public Good. Economics Bulletin, 3(8), 1-14.

[12] Cheng, I., Raina, S. and Xiong, W. (2014). Wall Street and the Housing Bubble. American Economic Review, 104(9), 2797-2829.

[13] Cipriani, M. and Guarino, A. (2005). Herd Behavior in a Laboratory Financial Market. American Economic Review, 95(5), 1427-1443.

[14] Cutler, D. M., Glaeser E. L. and Vigdor, J. L. (1999). The Rise and Decline of the American Ghetto. Journal of Political Economy, 107(3), 455-506.

[15] Dawes, R., McTavish, J., and Shaklee, H. (1977). Behavior, Communication and Assumptions about Other People's Behavior in a Common Dilemma Situation. Journal of Personality and Social Psychology, 35, 1-11.

[16] Gentzkow, M. and Shapiro, J. M. (2011). Ideological Segregation Online and Offline. Quarterly Journal of Economics, 126(4), 1799-1839.

[17] Glaeser, E. and C. Sunstein. (2009). Extremism and Social Learning. Journal of Legal Analysis, 1(1), 263-324.

[18] Grinblatt, M., Titman, S. and Wermers, R. (1995). Momentum Investment Strategies, Portfolio Performance, and Herding: A Study of Mutual Fund Behavior. American Economic Review, 85(5), 1088-1105.

[19] Hergueux, J, and Jacquemet, N. (2014). Social Preferences in the Online Laboratory: A Randomized Experiment. Experimental Economics, 18(2), 251-283

[20] Horton, J. J., Rand, D. G. and Zeckhauser, R. J. (2011). The Online Laboratory: Conducting Experiments in a Real Labor Market. Experimental Economics, 14(3), $399-425$.

[21] Isaac, R., and Walker, J. (1988). Communication and Free Riding Behavior: the Voluntary Contributions Mechanism. Economic Inquiry, 26(4), 585-608. 
[22] Kandel, E. and Pearson N. (1995). Differential Interpretation of Public Signals and Trade in Speculative Markets. Journal of Political Economy, 103(4), 831-872.

[23] Kramer, A. D., Guillory, J. E. and Hancock, J. T. (2014). Experimental Evidence of Massive-scale Emotional Contagion through Social Networks. Proceedings of the National Academy of Sciences, 111(24), 8788-8790.

[24] Li, L. and Zhou, X. (2014). Does Money Really Talk? Evidences from Rewardfor-Feedback Mechanism in Alibaba's C2C Platform. Working Paper, available at: http://cms.sem.tsinghua.edu.cn/semcms/res_base/semcms_com_www/ upload/article/image/2014_4/11_28/9gpci3190su1.pdf.

[25] McGrath, K., Elbanna, A., Hercheui, M., Panagiotopoulos, P. and Saad, E. (2012). Exploring the Democratic Potential of Online Social Networking: The Scope and Limitations of E-participation. Communications of the Association for Information Systems, 30: Article No. 16.

[26] Mojzisch, A., Grouneva, L. and Schulz-Hardt, S. (2010). Biased Evaluation of Information during Discussion: Disentangling the Effects of Preference Consistency, Social Validation, and Ownership of Information. European Journal of Social Psychology, 40(6), 946-956.

[27] Muchnik, L., Aral, S. and Taylor, S. J. (2013). Social Influence Bias: A Randomized Experiment. Science, 341(6146), 647-651.

[28] Salganik, J. M., Dodds, S. P. and Watts, J. D. (2006). Experimental Study of Inequality and Unpredictability in Artificial Cultural Market. Science, 311(5762), 854-856.

[29] Susilo, Y. and Axhausen, K. W. (2014). Repetitions in Individual Daily Activitytravel-location Patterns: a Study Using the Herfindahl-Hirschman Index. Transportation, 41(5), 995-1011.

[30] Zheng, Y. and Wu, G. (2005). Information Technology, Public Space, and Collective Action in China. Comparative Political Studies, 38(5), 507-536. 


\section{Appendix}

\section{A Cellphone Screen Captures (for Inter-FS-II)}

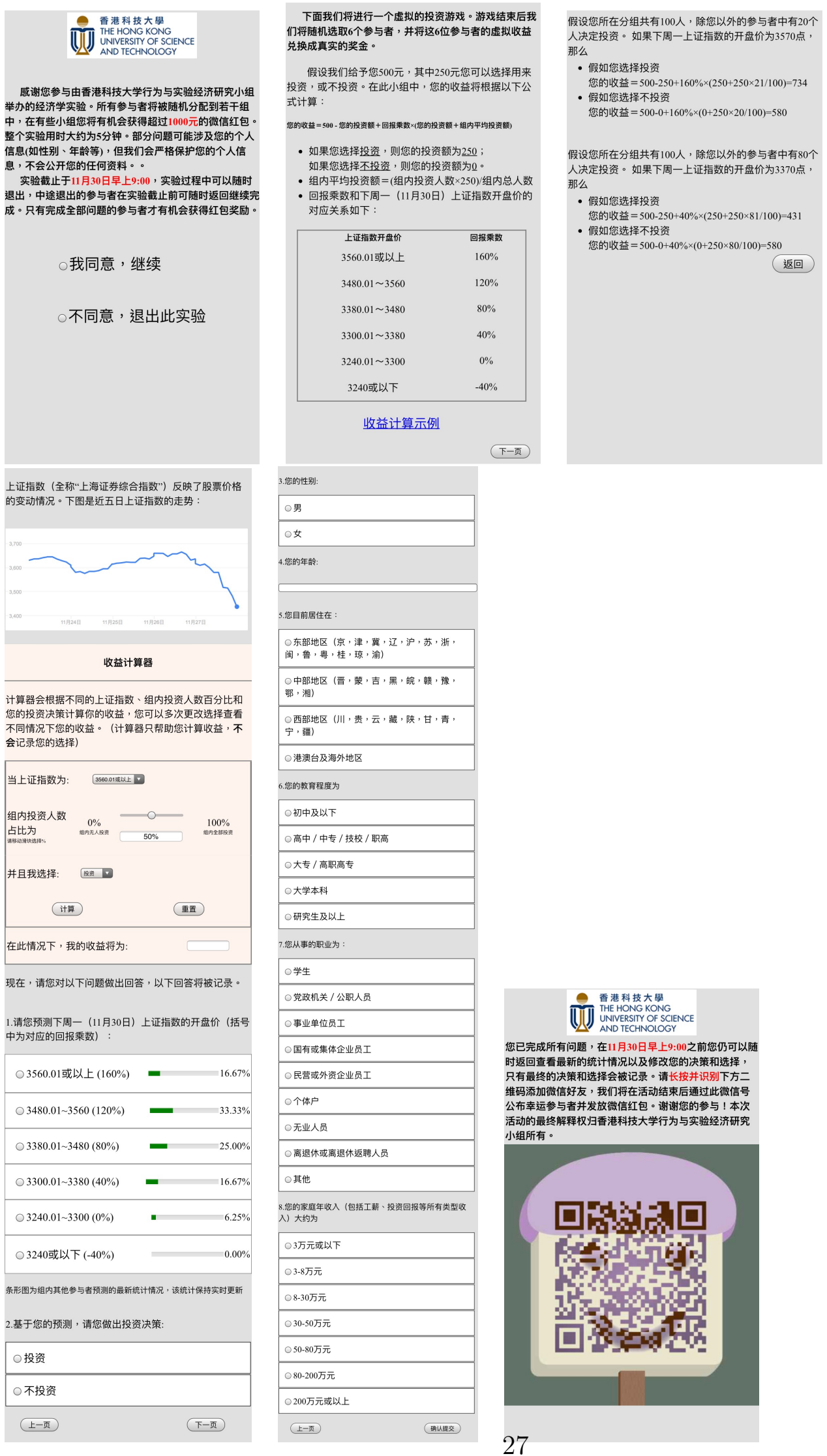




\section{B Instructions and Questionnaire in English (for Inter- FS-II)}

\section{B.1 Consent Form}

Thank you for participating in the economic experiment conducted by Hong Kong University of Science and Technology Behavioral and Experimental Economics Research Term. All participants will be randomly assigned to several groups and in some of the groups, you may have the chance to obtain a cash payment over 1000 RMB. The experiment would take about 5 minutes to complete. Some of the questions may be privacy related (e.g. gender, age), but all of the information you provide will be kept confidential and used only for academic purpose. This experiment will be closed at 9:00 a.m. on Nov. 30 . Before that, you are welcomed to come back to change your answers. Cash payments will be available only to participants who complete all the questions.

I agree. Proceed.

I do not agree. Quit the experiment.

\section{B.2 Instruction}

We now invite you to participate in an artificial investment game. When the game is over, we will randomly pick 6 participants. They will be paid at the amount of their investment payoff in the game with Renminbi (RMB).

Suppose we provide you with 500RMB. You may choose to invest half of it, i.e. 250RMB, or not to invest at all. In your group, your payoff will be calculated according to the following function:

$$
P A Y O F F=500-I N V E S T+m \times(I N V E S T+\text { avg.GINVEST })
$$

- If you choose to invest, then $I N V E S T=250$;

if you choose not to invest, then INVEST $=0$. 
- avg.GINVEST is the average group investment amount calculated as

$$
\text { avg.GINVEST }=\frac{1}{N}\left(N^{*} \times 250\right)
$$

where $N$ is the total number of participant in your group, and $N^{*}$ is the number of participants choosing to invest in your group.

- $m$ is the return multiplier decided by the opening price of SCI on Nov. 30 as following:

\begin{tabular}{|c|c|}
\hline SCI & $m$ \\
\hline 3620.01 or above & $160 \%$ \\
\hline 3560.01 to 3620 & $120 \%$ \\
\hline 3480.01 to 3560 & $80 \%$ \\
\hline 3380.01 to 3480 & $40 \%$ \\
\hline 3300.01 to 3380 & $0 \%$ \\
\hline 3300 or below & $-40 \%$ \\
\hline
\end{tabular}

Shanghai Composite Index (or "SCI" for short) reflects the overall stock market price. Following is the latest 5-day trend of SCI:

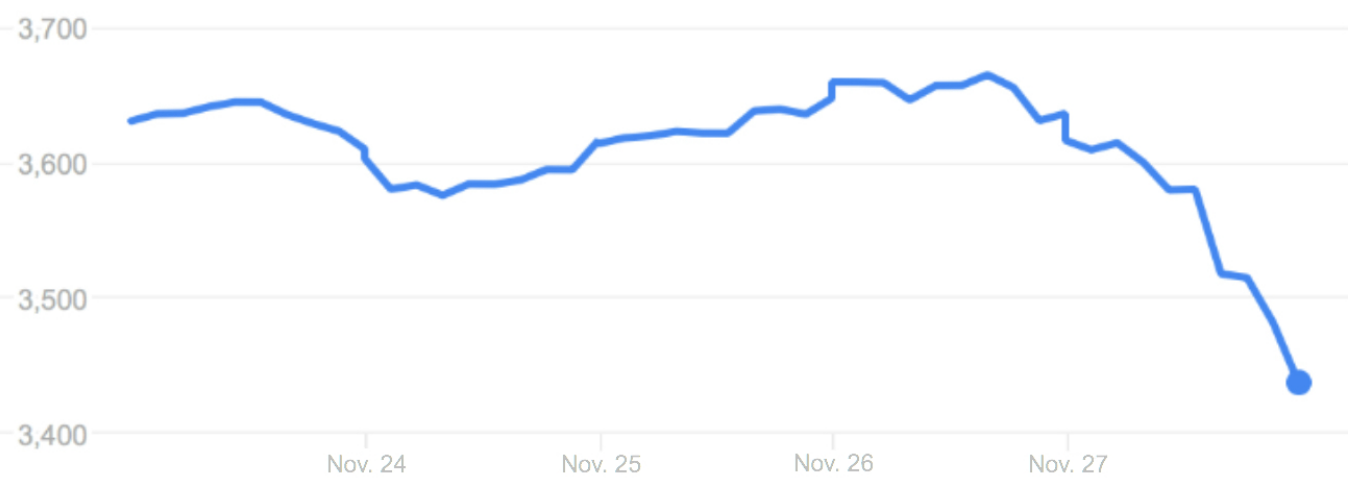

\section{B.3 Calculation Example}

Suppose there are 100 people in your group, and 20 of the 99 group members other than you decide to invest. If the opening price of SCI nest Monday is 3570, then 
- if you choose to invest

$$
\text { payoff }=500-250+120 \% \times(250+250 \times 21 / 100)=613
$$

- if you choose NOT to invest

$$
\text { payoff }=500-0+120 \% \times(0+250 \times 20 / 100)=560
$$

Suppose there are 100 people in your group, and 80 of the 99 group members other than you decide to invest. If the opening price of SCI nest Monday is 3370, then

- if you choose to invest

$$
\text { payoff }=500-250+0 \% \times(250+250 \times 81 / 100)=250
$$

- if you choose NOT to invest

$$
\text { payoff }=500-0+0 \% \times(0+250 \times 80 / 100)=500
$$

\section{B.4 Calculator Instruction}

This calculator returns the payoff according to the input of SCI, of the percentage of group member investing and of the investment decision. You may adjust your selection for as many times to check your payoff under different circumstances. (None of your selections here will be recorded.)

\section{B.5 Questions}

- Question 1: Please make a forecast of the opening price of SCI on next Monday (Nov. 30) (corresponding return multiplier in parenthesis):

$$
\begin{aligned}
& \text { - A. } 3620.01 \text { or above }(160 \%) \\
& \text { - B. } 3560.01 \text { to } 3620(120 \%) \\
& \text { - C. } 3480.01 \text { to } 3560(80 \%) \\
& \text { - D. } 3380.01 \text { to } 3480(40 \%) \\
& \text { - E. } 3300.01 \text { to } 3380(0 \%) \\
& \text { - F. } 3300 \text { or below }(-40 \%)
\end{aligned}
$$


- Question 2: Based on your forecast, please make your investment decision:
- A. Invest
- B. NOT to invest 


\section{Statistical Procedures}

\section{C.1 Comparisons of $\mathrm{HHI}$}

In an approach similar to Salganik, Dodds and Watts (2006), we adopt the following procedure to statistically compare the HHI between baseline and forecast sharing groups:

Step 1 Randomly and evenly split the baseline treatment into two groups and calculate the resulting HHI for 6 times;

Step 2 Conduct the Mann-Whitney U test on HHI between the forecast sharing groups and the baseline groups (using the calculation in Step 1) and record the $p$-value;

Step 3 Repeat Step 1 to 2 for 1000 times.

The bars in figure 1 for the baseline groups are the means of the 1000 simulations (each including 6 simulated HHIs). The following table reports the frequency of not having significantly higher value in the forecast sharing treatment than in the baseline treatment under various scenarios. ${ }^{8}$

Table 7: Comparisons of HHI

\begin{tabular}{|l|c|c|}
\hline & \multicolumn{2}{|c|}{ World I } \\
\hline \hline & Interdependent Project & Independent Project \\
\hline Frequency & $<0.05$ & $<0.01$ \\
\hline & \multicolumn{2}{|c|}{ World II } \\
\hline & Interdependent Project & Independent Project \\
\hline Frequency & $<0.05$ & $<0.01$ \\
\hline $\begin{array}{l}\text { Note: Frequency represents the frequency of not having significantly higher value in } \\
\text { forecast sharing treatment than in baseline treatment. }\end{array}$
\end{tabular}

In both World I and World II, the frequency of not having significantly higher HHI in forecast sharing than in baseline groups in the 1000 simulations is less than 0.05 in the interdependent project and less than 0.01 in the independent project.

\footnotetext{
${ }^{8}$ Significance is defined as having $p-$ value $<0.05$, unless otherwise specified.
} 


\section{C.2 Comparisons of the dissimilarity index}

In order for the dissimilarity indices of forecast sharing treatments and of baseline treatments to be comparable, we follow a similar procedure as in the last subsection with an extra step (this procedure applies to both the analysis of option dissimilarity and that of treatment dissimilarity), in line with Salganik, Dodds and Watts (2006):

Step 1 Calculate the dissimilarity index for each 2 of the 6 forecast sharing groups and generate 15 indices;

Step 2 Randomly and evenly split the baseline treatment into two groups and calculate the resulting dissimilarity index for 15 times;

Step 3 Conduct the Mann-Whitney U test on dissimlarity index between the forecast sharing groups and the baseline groups (using the calculations in Steps 1 and 2) and record the $p$-value;

Step 4 Repeat Step 1 to 3 for 1000 times.

Figures 4 and 5 represent the average of the 15 dissimilarity indices for each of the forecastsharing groups, and the mean of the 1000 simulations (each generating 15 dissimilarity indices) for the baseline groups. Following a procedure similar to the comparison of HHI, we compare both the option dissimilarity of the correct options (i.e the option dissimilarity of option $D$ in World I and the option dissimilarity of option $C$ in World II) and the treatment dissimilarity, between forecast sharing treatments and baseline treatments. The following tables report the frequencies of not having significantly higher option dissimilarity for the correct option and treatment dissimilarity, respectively, in the forecast sharing treatment than in the baseline treatment under various scenarios. 
Table 8: Comparisons of Option Dissimilarity for the Correct Options

\begin{tabular}{|l|c|c|}
\hline & \multicolumn{2}{|c|}{ World I } \\
\hline \hline & Interdependent Project & Independent Project \\
\hline Frequency & $>0.1$ & $>0.1$ \\
\hline & \multicolumn{2}{|c|}{ World II } \\
\hline & Interdependent Project & Independent Project \\
\hline Frequency & $<0.05$ & $>0.1$ \\
\hline
\end{tabular}

Note: Frequency represents the frequency of not having significantly higher value in the forecast sharing treatment than in the baseline treatment.

Table 9: Comparisons of Treatment Dissimilarity

\begin{tabular}{|c|c|c|}
\hline & \multicolumn{2}{|c|}{ World I } \\
\hline \hline & Interdependent Project & Independent Project \\
\hline Frequency & $<0.1$ & $<0.05$ \\
\hline & \multicolumn{2}{|c|}{ World II } \\
\hline & Interdependent Project & Independent Project \\
\hline Frequency & $<0.01$ & $<0.01$ \\
\hline
\end{tabular}

Note: Frequency represents the frequency of not having significantly higher value in the forecast sharing treatment than in the baseline treatment. 